\title{
PELATIHAN PEMBUKUAN DAN PENCATATAN KEUANGAN SEDERHANA KEPADA SISWA/I YAYASAN PRIMA UNGGUL
}

\author{
Agus Munandar ${ }^{1 *}$, Iren Meita ${ }^{1}$ Lidwina Ribka Putritanti $^{1}$ \\ ${ }^{1}$ Jurusan Akuntansi, Fakultas Bisnis, Institut Teknologi dan Bisnis Kalbis, Jakarta, Indonesia \\ *Penulis Korespondensi : agus.munandar@kalbis.ac.id
}

\begin{abstract}
Abstrak
Siswa Yayasan Prima Unggul selalu aktif dalam melakukan kegiatan bisnis untuk membantu pemahaman mereka dalam kegiatan yang diberikan di kelas. Kegiatan yang mereka erat kaitannya dengan kegiatan bisnis, oleh karenanya diperlukan penambahan ilmu tentang pembukuan dan pencatatan untuk mendukung kegiatan bisnis atau usaha mereka, dimana apabila sejak dini sudah diajarkan kelak usaha UMKM yang mereka rintis dapat berhasil dan maju. Penawaran kerjasama tim PKM kepada mitra disambut dengan baik oleh Koordinator Bapak Martinus Gea dalam kegiatan PKM, Jakarta Timur. Mereka sangat mendukung dan antusias untuk dilaksanakannya kegiatan PKM, Kegiatan PKM yang telah dilaksanakan tanggal 22 Maret 2017 dievaluasi dalam rapat tim PKM di ruang rapat dosen lantai 2 kampus Kalbis Institute Jl. Pulomas Selatan Kav.22 JakTim pada tanggal 14 Maret 2017 jam 08.00 - 17.00 WIB. Para Siswa dan siswi yang sebelumnya belum terlalu paham pembukuan dan pencatatan keuangan sederhana mulai memahami manfaat dari pembukuan dan pencatatan keuangan sederhana.
\end{abstract}

Kata kunci: Pembukuan, UMKM, keuangan sederhana, Pencatatan

\begin{abstract}
Students of Yayasan Prima Unggul are always active in conducting business activities to assist their understanding in the activities provided in the classroom. Activities that they are closely related to business activities, therefore required additional knowledge about the bookkeeping and recording to support their business activities or business, where if from an early age has been taught later MSME business they pioneered can succeed and go forward. The PKM team's cooperation offer to the partners was welcomed by Coordinator Mr. Martinus Gea in PKM, East Jakarta. They are very supportive and enthusiastic for the implementation of PKM activities, PKM activities that have been held on March 22, 2017 evaluated in PKM team meeting in lecturers' conference room on 2nd floor of Kalbis Institute campus Jl. Pulomas Selatan Kav.22 JakTim on 14 March 2017 at 08.00 - 17.00 WIB. Students and students who have not been too familiar with simple bookkeeping and record keeping begin to understand the benefits of simple bookkeeping and recording.
\end{abstract}

Keywords: Bookkeeping, UMKM, simple finance, Recording

\section{PENDAHULUAN}

Pada sharia economic outlook 2014 menurut data Badan Pusat Statistik menunjukan jumlah pelaku UMKM mencapai $99 \%$ dari sejumlah pelaku usaha di Indonesia, nilai investasi UMKM mencapai 52,9\% dari total investasi. Oleh karenanya dibutuhkan pencatatan dan pembukuan yang baik untuk usaha UMKM terlebih lagi pada usia muda pada anak-anak SMA

Pembukuan adalah suatu proses pencatatan yang dilakukan secara teratur untuk mengumpulkan data dan informasi keuangan yang meliputi harta, kewajiban, modal, penghasilan, dan biaya, serta jumlah harga perolehan dan penyerahan barang atau jasa, yang ditutup dengan menyusun laporan keuangan berupa neraca, dan laporan laba rugi untuk periode tahun pajak tersebut. Sedangkan pencatatan adalah pengumpulan data yang dikumpulkan secara teratur tentang peredaran atau penerimaan bruto dan/atau penghasilan bruto sebagai dasar untuk menghitung jumlah pajak yang terutang.

Siswa Yayasan Prima Unggul selalu aktif dalam melakukan kegiatan bisnis untuk membantu pemahaman mereka dalam kegiatan yang diberikan di kelas. Kegiatan yang mereka erat kaitannya dengan kegiatan bisnis, oleh karenannya diperlukan penambahan ilmu tentang pembukuan dan pencatatan untuk mendukung kegiatan bisnis atau usaha mereka, dimana apabila sejak dini sudah diajarkan kelak usaha UMKM yang mereka rintis dapat berhasil dan maju. 


\section{KAJIAN PEMBAHASAN TEMA PKM}

\subsection{Pencatatan dan Pembukuan}

Pencatatan adalah setiap transaksi dari suatu kegiatan usaha merupakan suatu informasi awal yang harus dicatat dan diolah, sehingga terbentuk sebuah laporan keuangan. Pembukuan adalah suatu proses pencatatan yang dilakukan secara teratur untuk mengumpulkan data dan informasi keuangan yang meliputi harta, kewajiban, modal, penghasilan dan biaya, serta harga perolehan dan penyerahan barang atau jasa, yang ditutup dengan menyusun laporan keuangan berupa neraca, dan laporan laba rugi untuk periode Tahun Pajak tersebut". Menurut Pasal 1 angka 26 UU KUP

\subsection{Pendukung Pencatatan dan Pembukuan Sederhana}

1) Faktur Faktur adalah bukti penjualan barang yang dilakukan secara kredit yang dibuat oleh pihak penjual dan diberikan kepada pihak pembeli.

2) Kwitansi merupakan bukti transaksi bahwa yang bersangkutan telah menerima uang atau telah membayar uang secara tunai.

3) Nota Kredit Bukti transaksi penerimaan kembali barang yang telah dijual secara kredit (retur penjualan), atau pengurangan harga faktur karena barang sebagian rusak atau kualitas yang tidak sesuai dengan pesanan. Dalam hal demikian nota kredit dibuat oleh pihak penjual dan dikirimkan kepada pihak pembeli.
4) Nota Debit Bukti transaksi pengiriman kembali barang yang dibeli karena sebagian barang yang dibeli ada yang rusak atau tidak sesuai pesanan. Maka, nota debet dibuat oleh pembeli untuk dikirimkan kepada penjual.

\subsection{Tujuan dari Pencatatan dan Pembukuan Sederhana}

Agar dapat mempermudah suatu keluarga dalam mengelola keuangan keluarga sehingga dapat direncanakan dengan sebaik-baiknya. Selain itu untuk mengkalkulasi, mengkontrol serta mengatur keseluruhan transaksi keuangan yang terjadi sepanjang keberlangsungan dunia usahanya.

\subsection{Pengertian aset, liabilities, dan equity}

Aset adalahsumber ekonomi yang diharapkan memberikan manfaat usaha di kemudian hari

Liabilities (hutang) Kewajiban suatu badan usaha / perusahaan kepada pihak ketiga yang dibayar dengan cara menyerahkan aktiva atau jasa dalam jangka waktu tertentu sebagai akibat dari transaksi di masa lalu.

Equity sesuatu yang digunakan untuk mendirikan atau menjalankan suatu usaha.

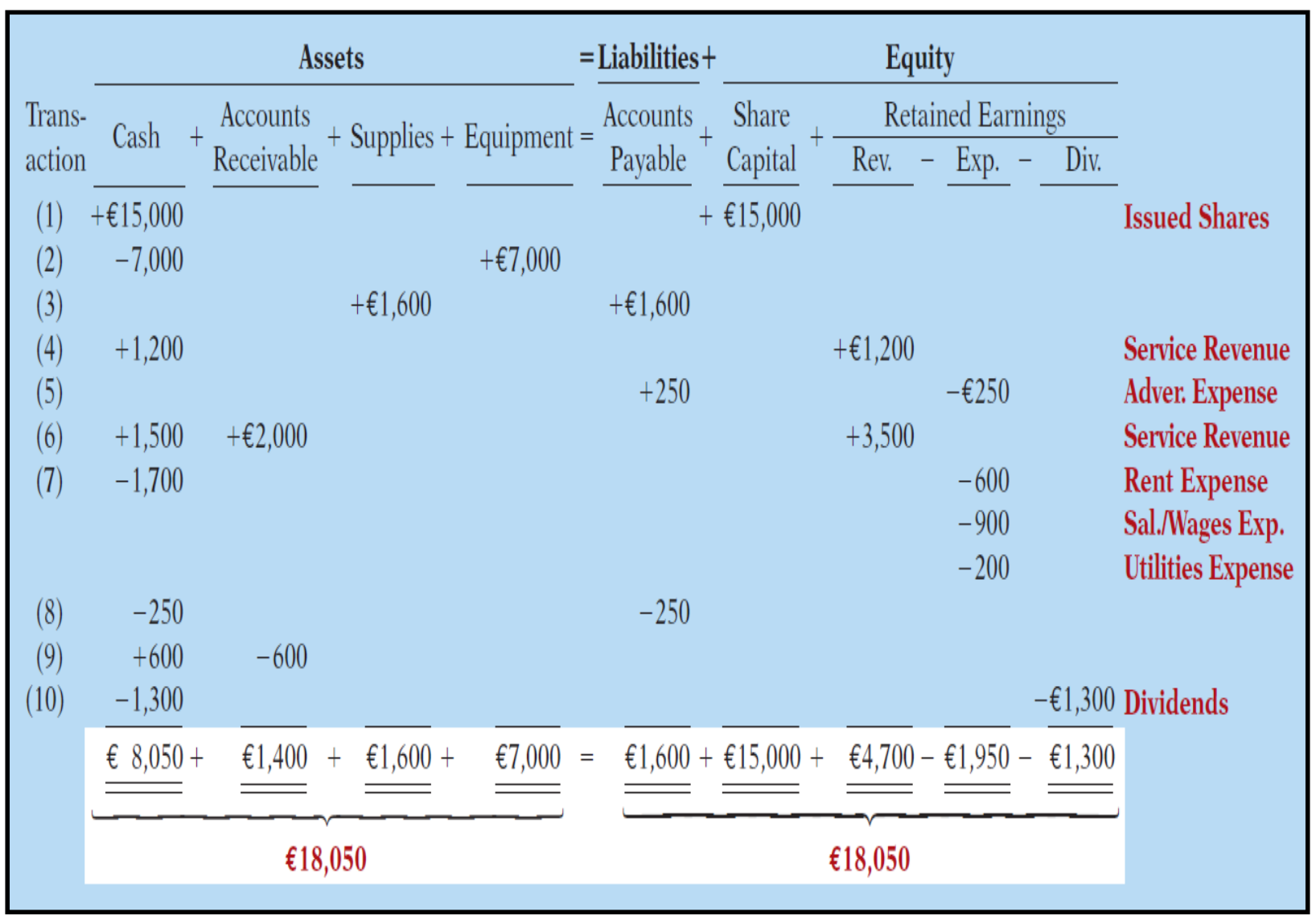




\subsection{Laporan keuangan}

\begin{tabular}{|c|c|c|}
\hline \multicolumn{3}{|c|}{$\begin{array}{c}\text { Softbyte Inc. } \\
\text { Income Statement } \\
\text { For the Month Ended September 30, } 2014\end{array}$} \\
\hline $\begin{array}{l}\text { Revenues } \\
\text { Service revenue }\end{array}$ & & $€ 4,700$ \\
\hline $\begin{array}{l}\text { Expenses } \\
\text { Salaries and wages expense } \\
\text { Rent expense } \\
\text { Advertising expense } \\
\text { Utilities expense }\end{array}$ & $\begin{array}{r}€ 900 \\
600 \\
250 \\
200 \\
\end{array}$ & \\
\hline $\begin{array}{l}\text { Total expenses } \\
\text { Net income }\end{array}$ & & $\frac{1,950}{€ 2,750}$ \\
\hline $\begin{array}{r}\text { Soft } \\
\text { Retained Ea } \\
\text { For the Month Enc }\end{array}$ & 2014 & \\
\hline $\begin{array}{l}\text { Retained earnings, September } 1 \\
\text { Add: Net income }\end{array}$ & & $\begin{array}{r}\mathrm{O} \\
2,750 \\
\end{array}$ \\
\hline Less: Dividends & & $\begin{array}{r}2,750 \\
1,300 \\
\end{array}$ \\
\hline Retained earnings, September 30 & & $€ 1,450$ \\
\hline
\end{tabular}

\section{Softbyte Inc. Retained Earnings Statement For the Month Ended September 30, 2014}

Retained earnings, September 1

Add: Net income

Less: Dividends

Retained earnings, September 30

\begin{tabular}{|c|c|}
\hline \multicolumn{2}{|c|}{$\begin{array}{c}\text { Softbyte Inc. } \\
\text { Retained Earnings Statement } \\
\text { For the Month Ended September 30, } 2014\end{array}$} \\
\hline Retained earnings, September 1 & $€ \quad 0$ \\
\hline Add: Net income & 2,750 \\
\hline Jecc. Dividends & $\begin{array}{l}2,750 \\
1,300\end{array}$ \\
\hline Retained earnings, September 30 & $€ 1,450$ \\
\hline
\end{tabular}

\section{Softbyte Inc.}

Statement of Financial Position

September 30, 2014

\begin{tabular}{|c|c|c|}
\hline \multicolumn{3}{|c|}{ Assets } \\
\hline Equipment & & $€ 7,000$ \\
\hline Supplies & & 1,600 \\
\hline Accounts receivable & & 1,400 \\
\hline Cash & & 8,050 \\
\hline Total assets & & $\overline{€ 18,050}$ \\
\hline \multicolumn{3}{|c|}{ Equity and Liabilities } \\
\hline \multicolumn{3}{|l|}{ Equity } \\
\hline Share capital_ordinary & $€ 15,000$ & \\
\hline Retained earnings & $1,450 \longleftarrow$ & $€ 16,450$ \\
\hline \multicolumn{3}{|l|}{ Liabilities } \\
\hline Accounts payable & & 1,600 \\
\hline Total equity and liabilities & & $€ 18,050$ \\
\hline
\end{tabular}




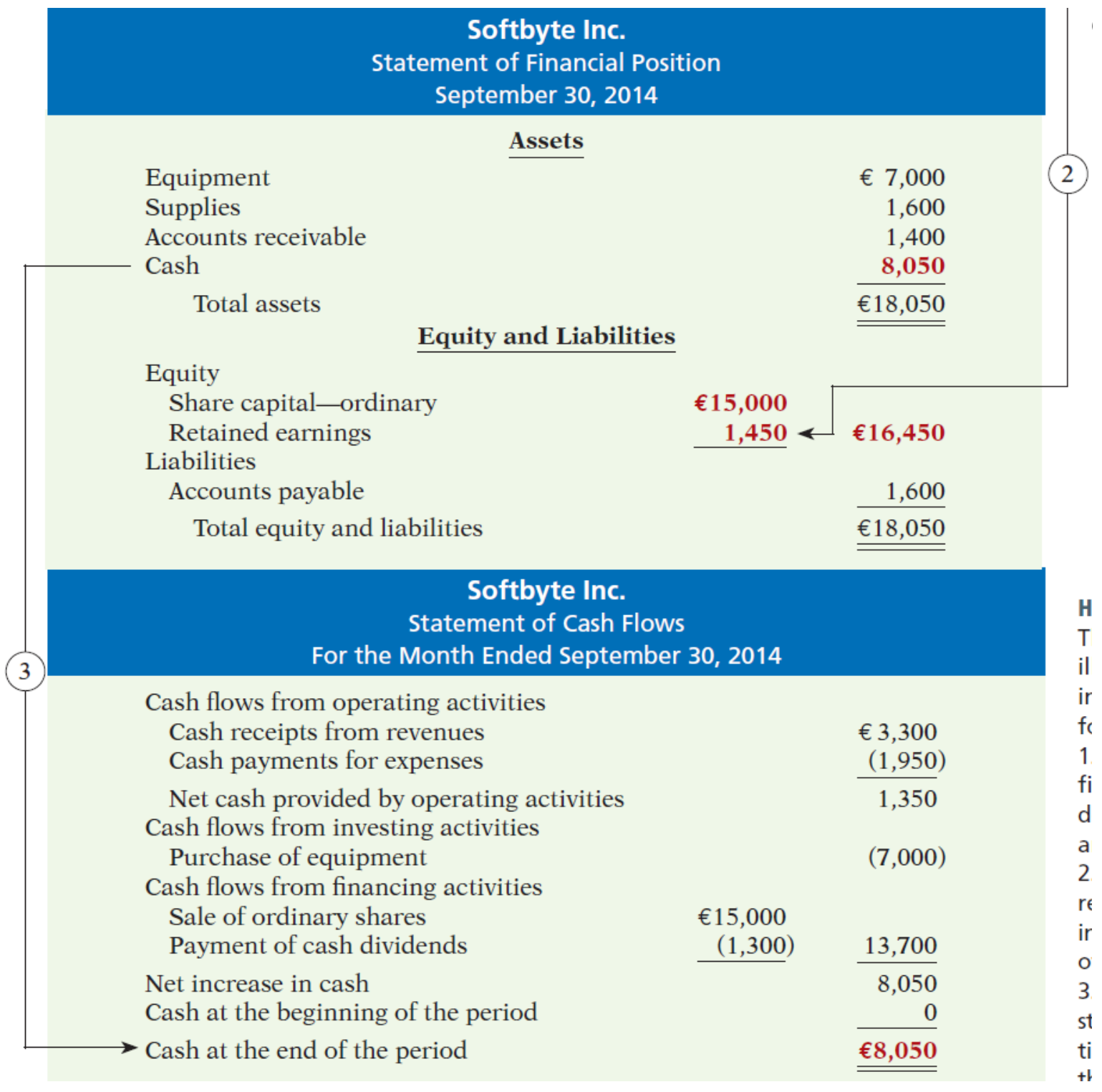

\subsection{Kiat Mengelola Keuangan Usaha}

Potensi penghasilan tidak terbatas adalah Membuka usaha dapat memberi potensi penghasilan pribadi yang tidak terbatas. Bedakan istilah "kaya" dan "penghasilan tinggi".

Kiat pertama adalah Pisahkan Keuangan Usaha dengan Keuangan Pribadi , kiat kedua adalah Kendalikan Pemasukan dan Pengeluaran Keuangan Anda , Kiat ketiga proteksi, kiat keempat miliki investasi selain usaha, kiat keempat Lakukan Analisis Ketika Ingin Membuka Usaha Baru

\section{PELAKSANAAN PKM DAN HASIL PKM}

\subsection{Perencanaan Kegiatan PKM}

Rencana ini didiskusikan dalam rapat Tim Dosen Program Studi Akuntansi Fakultas Ekonomi Institut Teknologi dan Bisnis Kalbis (Kalbis Institute) yang tergabung kedalam Tim Pengabdian Kepada Masyarakat (PKM) pada 02 Februari 2017 jam 08.00 - 17.00 WIB di ruang rapat dosen Lantai 2 Kampus Institut Teknologi

Diskusi ini untuk membicarakan PKM yang merupakan salah satu wujud Tri Dharma Perguruan Tinggi. Hasilnya adalah kesepakatan untuk melakukan PKM dengan mitra Yayasan Prima Unggul. Alasan utama untuk melakukan PKM dengan mitra Yayasan Prima Unggul, Jakarta Timur adalah karena lokasinya yang tidak terlalu jauh dari kampus Institut Teknologi dan Bisnis Kalbis (Kalbis Institute), yaitu berjarak sekitar $9 \mathrm{~km}$ serta untuk menambah pengetahuan tentang pembukuan dan pencatatan keuangan sederhana untuk usaha.

\subsection{Observasi Awal Tim PKM Ke Yayasan} Prima Unggul, Jakarta Timur

Kegiatan observasi tim PKM ke RPTRA Cibesut, Jakarta Timur dilakukan pada tanggal 30 Januari 2017 oleh Tim Dosen Program Studi Akuntansi Fakultas Ekonomi Institut Teknologi dan Bisnis Kalbis (Kalbis Institute) yang 
tergabung dalam Tim Pengabdian Kepada Masyarakat. Tim PKM disambut oleh Bapak Martinus Gea selaku Ketua YPU dan para siswa Yayasan Prima Unggul. Pada pertemuan ini dilakukan pembicaraan awal dan perkenalan antara tim PKM Kalbis dengan Koordinator Yayasan Prima Unggul.

Tujuan diadakannya observasi awal adalah untuk menggali kembali persoalan serta kebutuhan para siswa dan siswi tentang pembukuan dan pencatatan keuangan sederhana.

\subsection{Penawaran Kerjasama Dengan Mitra PKM (Observasi Lanjut)}

Tim PKM mengadakan observasi lanjut pada tanggal 13 Februari 2017, pukul 08.00-17.00 WIB untuk menawarkan kerjasama Koordinator PKM prodi akuntansi dengan Yayasan Prima Unggul, Jakarta Timur Bapak Martinus Gea dalam kegiatan PKM yaitu memberikan pelatihan kepada Siswa dan siswi YPU Jakarta Timur sebagai penambah pengetahuan dalam pembukuan dan pencatatan keuangan sederhana para. Kunjungan ini di sambut baik oleh Bapak Martinus Gea selaku Ketua YPU, Jakarta Timur.

\subsection{Kesediaan Bekerjasama Dari Mitra PKM}

Penawaran kerjasama tim PKM kepada mitra disambut dengan baik oleh Koordinator Bapak Martinus Gea dalam kegiatan PKM, Jakarta Timur. Mereka sangat mendukung dan antusias untuk dilaksanakannya kegiatan PKM yang berbentuk pelatihan untuk siswa dan siswi, Jakarta Timur yang bertempat di Kampus Institut Teknologi dan Bisnis Kalbis (Kalbis Institute). Kesediaan bekerja sama disampaikan pada saat observasi lanjut yang dilaksanakan pada tanggal 13 Februari 2017 oleh pihak YPU kepada Tim PKM.

\subsection{Penyusunan Proposal Dan Pembuatan Materi Pelatihan}

Dalam rapat Tim PKM pada 14 Maret 2013, jam 08.00 -17.00 WIB di ruang rapat dosen Lantai 2 Kampus Institut Teknologi dan Bisnis Kalbis (Kalbis Institute) Jalan Pulomas Selatan Kav.22 Jakarta Timur dibicarakan program dan tema PKM yang diberikan bagi siswa dan siswi YPU, Jakarta Timur. Hasilnya adalah kesepakatan untuk mengadakan PKM dengan tema "Pelatihan Pembukuan dan Pencatatan Keuangan Kepada Siswa/i Yayasan Prima Unggul". pada tanggal 22 Maret 2017 yang bertempat di AR 305 Kalbis Institute di Jalan Pulomas Selatan Kav.22 Jakarta Timur.

\subsection{Penugasan PKM oleh Koordinator P3KM ITBK}

Penugasan kegiatan PKM dengan mitra yaitu Yayasan Prima Unggul, Jakarta Timur ditunjukkan dengan adanya Surat Tugas yang ditandatangani oleh kepala biro P3KM Kalbis Institute.

3.7. Koordinasi tim PKM dengan Ibu-Ibu PKK Cipinang Besar Utara

Koordinasi tentang kepastian pelaksanaan dan ketersediaan waktu Ibu-ibu PKK Cibesut untuk mengikuti pelatihan ini dilakukan lewat telepon sambil mengingatkan kembali akan pelatihan yang akan dilaksanakan tanggal 22 Maret 2017 pada pukul 08.30-11.30 WIB.

Kegiatan pelatihan dilaksanakan pada hari Jumat tanggal 22 Maret 2017 pada pukul 08.30-11.30 WIB di Ruang AR 305 Lantai 3 Kampus Kalbis Institute Jalan Pulomas Selatan Kav.22 Jakarta Timur. Pelatihan diberikan oleh Tim PKM dari Prodi Akuntansi yang berjumlah sebanyak 4 (Empat) orang dosen dan didampingi oleh 2 (dua) orang mahasiswa. Peserta pelatihan adalah siswa dan siswi YPU yang berjumlah 40 orang.

Acara dimulai dengan meregistrasi peserta dan pembukaan jam 08.30-09.00 WIB, pembukaan oleh Ketua Tim pengusul Agus Munandar S.E.,M.Sc.

Jam 09.00-09.45 WIB acara dilanjutkan dengan pelatihan, materi pelatihan pertama diberikan Iren Meita S.E Ak M.Ak tentang teori pembukuan dan pencatatan keuangan sederhana kepada Ibu-ibu PKK Cibesut pada sesi ini didampingi oleh Ibu Presti Rosiana, S.E.,M.Ak.,Ak.,CA dan Ibu Lidwina Ribka Putritanti, S.E.,M.Ak. Dilanjutkan praktik pada jam 09.45-10.30 oleh Ibu Presti Rosiana, S.E.,M.Ak.,Ak.,CA dan Ibu Lidwina Ribka Putritanti, S.E.,M.Ak

Jam 10:30-11:00 WIB acara dilanjutkan dengan materi pelatihan berjudul Kiat Mengelola Keuangan Usaha oleh Ibu Lidwina Ribka Putritanti, S.E.,M.Ak. Selanjutnya agar peserta semakin tertarik untuk mengikuti pelatihan diadakan kuis kecil dengan pembagian doorprize kepada 5 orang pemenang pada jam 11:00-11:30.

3.8. Evaluasi dan pembuatan laporan akhir kegiatan PKM

Kegiatan PKM yang telah dilaksanakan tanggal 22 Maret 2017 dievaluasi dalam rapat tim PKM di ruang rapat dosen lantai 2 kampus Kalbis Institute Jl. Pulomas Selatan Kav.22 JakTim pada tanggal 14 Maret 2017 jam 08.00 - 17.00 WIB. Pada kegiatan ini dibahas masukan-masukan yang mungkin dilakukan pada pelatihan berikutnya, dan juga pembuatan laporan akhir kegiatan PKM dengan mitra Yayasan Prima Unggul. 


\section{KESIMPULAN}

Sehubungan dengan uraian di atas, dapat disimpulkan bahwa kegiatan pelatihan yang telah dilakukan pada tanggal 22 Maret 2017 adalah :

a. Para Siswa dan siswi terlihat sangat antusias mengikuti materi yang diberikan oleh para instruktur.

b. Suasana pada saat pelatihan sangat aktif, dimana para siswa dan siswi memiliki keingintahuan yang begitu besar terhadap tiap materi yang diberikan.

c. Pelatihan yang diberikan sangat membantu para siswa dan siswi dalam memahami pembukuan dan pencatatan keuangan sederhana.

d. Para Siswa dan siswi yang sebelumnya belum terlalu paham pembukuan dan pencatatan keuangan sederhana mulai memahami manfaat dari pembukuan dan pencatatan keuangan sederhana.

\section{SARAN}

Dengan memperhatikan besarnya minat peserta mengikuti pelatihan ini, maka:

Disarankan untuk dapat diberikan pelatihan lanjutan tentang perhitungan persediaan dan pembukuan dan pencatatan untuk usaha dagang terlebih pada perhitungan Harga Pokok Penjualan.

\section{DAFTAR PUSTAKA}

Weygandt, Jerry J and Kieso, Donald E and Kimmel, Paul D, Accounting Principles Pengantar Akutansi, Edisi Ketujuh, Penerbit Salemba Empat, Jakarta, 2007

Ikatan Akuntan Indonesai, Standar Akutansi Keuangan, penerbit salemba Empat, Jakarta, 2007 